\title{
The Kinematics Model Establishment of Crank Linkage with Time under Low Speed in Vehicle
}

\author{
Xu Run ${ }^{*}$, Liu Jiaguang \\ Mechanical Electric Department, WenJing College, Yamtai University, Yantai 264005, China
}

\author{
DOI: $\underline{10.36348 / \text { sjet.2021.v06i04.004 }}$ \\ | Received: 17.03.2021 | Accepted: 24.04.2021 | Published: 27.04.2021
}

*Corresponding author: Xu Run

\section{Abstract}

With inclining the velocity of vehicle the cost will become low dominantly when the velocity attains $19 \mathrm{Km} / \mathrm{h}$ and $26 \mathrm{Km} / \mathrm{h}$ in future. With increasing time the movement, the velocity and acceleration of vehicle will become sinusoidal wave. When the crank length increases from $70 \mathrm{~mm}$ to $100 \mathrm{~mm}$ under linkage length $\mathrm{L}=180 \mathrm{~mm}$ the maximum movement, velocity and acceleration will increase and the minimum ones will increase. The phase angle will decline with inclining speed with sinusoidal wave but the size of them maintains unchanged respectively. So it is chosen of the short crank and long linkage so as to maintain maximum force. To be rapid work the speed is needed highly.

Keywords: Time, speed, crank length, linkage length, acceleration, vehicle, modeling, kinematics.

Copyright (C) 2021 The Author(s): This is an open-access article distributed under the terms of the Creative Commons Attribution 4.0 International License (CC BY-NC 4.0) which permits unrestricted use, distribution, and reproduction in any medium for non-commercial use provided the original author and source are credited.

\section{INTRODUCTION}

The velocity and acceleration is to be found the necessary parameters in crank mechanism movement in kinematics of vehicle. So in a cycle the investigation into kinematic movement is important. Firstly through velocity of vehicle exhibits the force size directly. It is observed through curve tendency. Secondly the acceleration expresses the force through detail tendency. It is expressed that define value of force change. In order to save material and cost the data on them is essential at all. Such as the detail material choice and manufacture cost is needed reasonably and economically. In this paper the velocity and acceleration is computed through model and it is valuable on there data and tendency. Further research is needed to these parameters behavior to grasp these rule and data. Because the vehicle is applied to many factories the crank is a important mechanism in punch component [1-4]. So the speed of work is most important one to control the production. We shall compute and model the parameter to find a economic mechanism to its application to product designer, operating engineer and machine maker.

The dynamics can be used in crank and linkage parts on the low velocity of $19 \mathrm{Km} / \mathrm{h}$ and $26 \mathrm{Km} / \mathrm{h}$ which is the motorcycle velocity in general so as to compare with it, because its piston can work through the them. In the process of designing, the piston press are connected into their procedures, and in a short time to complete the continuous processing of the piston circulation [5$6]$. They produce a lot of products in a certain amount of time. Since the they are an automatic movement vehicle, it is difficult to control the control. So we should focus on this control issue and work for scientific management, networking and digital design and management. Due to excessive piston and crank mechanism fatigue, and the piston processing speed is also fast, we need to carry out timely routine inspection of the engine and focus on the hidden faults. This saves the cost of the inspection to the manufacturer's personnel for repair due to machine failure and the loss caused by the fault of the machine. Because the load and frequency of the mechanism does not keep up with the loss caused by the fatigue condition under the load of the vehicle and the engine in special, the economic efficiency of the control structure of the crankshaft with related parts is an important factor in the vehicle. This paper discusses the crankshaft from the technical view of economic benefit. The crank is the most critical transmission power mechanism, which turns the rotating motion of the crank and linkage into the speed of the engine and pushes and presses the piston surface. Therefore, the kinematics and dynamics of the crank are studied in order to optimize the crank parameters and high efficiency. 


\section{Kinematic Equations}

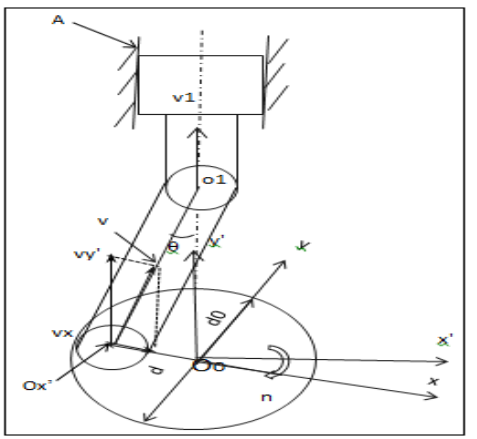

Fig-1: The kinematic of crankshaft linkage length in the engine of vehicle

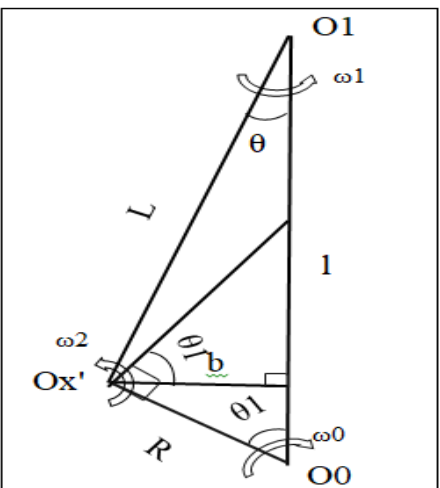

Figure-1 shows the kinematics diagram of crankshaft connecting rod device. The center of the coordinate system $\mathrm{x}-\mathrm{y}$ is $\mathrm{O}_{0}$, the crankshaft is the $\mathrm{OxO}_{0}$ part, and the $\mathrm{O}_{0}$ circular axis is the drive axis, which rotates $\mathrm{n}(\mathrm{r} / \mathrm{m})$. Connect the die $\mathrm{O}_{1} \mathrm{~A}$ through $\mathrm{O}_{0} \mathrm{O} 1 . \mathrm{O}_{1} \mathrm{~A}$ in the $x^{\prime}-y^{\prime}$ coordinate system moves back and forth in a straight line in the $y^{\prime}$ direction of the orbit, moving at speed $\mathrm{v}_{1}$. In frame $\mathrm{x}$ prime minus $\mathrm{y}$ prime, $\mathrm{v}_{1}$ is equal to v sub y prime. Angle theta is the Angle between the die and the crank. A is the die acceleration; $\mathrm{D}$ is the length of the crank, that is, the diameter of the crank; $\mathrm{D}_{0}$ is the diameter of the drive shaft. As shown in Figure-3, the vehicle is $\mathrm{O}_{1} \mathrm{~A}$ in Figure-1. Where $\mathrm{a}$ is the vehicle acceleration, $\mathrm{d} 1$ and 11 are the diameter and length of the first vehicle. Assuming that all the forces are the same as F, it is only necessary to analyze the force on the driving vehicle. The force analysis process is as follows.

The final member of the connecting rod structure by the crankshaft, namely the section $\mathrm{O}_{0} \mathrm{Ox}^{\prime}$ in the figure.

Fig-2: The kinematic of crankshaft linkage length

From Figure-2 it has

$$
\begin{aligned}
& L / \sin \theta_{1}=R / \sin \theta \ldots \ldots \ldots \ldots \ldots \ldots \\
& \text { So } \theta=\arcsin \left[\frac{R \sin (2 \pi n t / 60)}{L}\right] .
\end{aligned}
$$

It is formula for $\theta$ of vehicle and linkage.

$$
\begin{aligned}
& \text { Here } \theta_{1}=2 \pi n t / 60 \\
& \text { Since } \Delta l=L\left(\cos \theta_{1}-1\right)+R \cos \theta+R \\
& \text { So } \Delta l=L[\cos (2 \pi n t / 60)-1]+2 R \cos ^{2} \frac{\arcsin [R \sin (2 \pi n t / 60) / L]}{2} \text {.... }
\end{aligned}
$$

Square (1) it has

$$
\frac{R^{2}}{L^{2}} \sin ^{2} \theta_{1} / 2 \cos ^{2} \theta_{1} / 2=\left(1-\sin ^{2} \theta / 2\right) \sin ^{2} \theta / 2
$$

Solve it has

$$
\Delta l=L\left(\cos \theta_{1}-1\right)+2 R\left[1-\frac{1 \pm \sqrt{1+\left(\frac{R}{L} \sin \theta_{1}\right)^{2}}}{2}\right]
$$


It is formula for mod relative length movement. As below the velocity and acceleration of vehicle.

$$
\begin{aligned}
& v_{1}=\frac{d \Delta l}{d t} \\
& a=\frac{d v_{1}}{d t} .
\end{aligned}
$$

Here, $\mathrm{n}$ is speed in shaft, $\mathrm{r} / \mathrm{min}$; $\mathrm{L}$ is the linkage length; $\mathrm{R}$ is crank length; $\mathrm{d}$ is the shaft diameter; $\mathrm{a}$ is acceleration of vehicle; $\theta$ is angle of linkage and center line; $\theta_{1}$ is angle of crank and center line; $\mathrm{t}$ is the time; $\Delta \mathrm{L}$ is the relative vehicle movement [2].

\section{DISCUSSIONS}

It is investigated that what the velocity changes when crank length $\mathrm{R}$ inclines from $40 \mathrm{~mm}$ to $70 \mathrm{~mm}$ in vehicle of machine meanwhile what the velocity changes when the speed becomes from $300 \mathrm{r} / \mathrm{m}$ to $400 \mathrm{r} / \mathrm{m}$ during one cycle course time is detailed explanation in this study. The size of crank length is chosen reasonably for optimum vehicle length. It is investigated which $\mathrm{R}=70 \mathrm{~mm}, 85 \mathrm{~mm}$ and $100 \mathrm{~mm}$ under $\mathrm{L}=140 \mathrm{~mm}, 160 \mathrm{~mm}$ and $180 \mathrm{~mm}$ is the best one since its energy saving is attained not only, but also the fit vehicle work size with $14 \mathrm{~cm}, 17 \mathrm{~cm}$ and $20 \mathrm{~cm}$ which is the lowest to compare with others in this study. The longest size is for $\mathrm{R}=100 \mathrm{~mm}$ and $\mathrm{L}=180 \mathrm{~mm}$ which has the $20 \mathrm{~cm}$ one for the deepest vehicle. When the $\Delta \mathrm{l}$ is functional it is considered that it is differential $\mathrm{dl}$, then it is used that differential $\mathrm{dl} / \mathrm{dt}$ is to be integrated the whole cycle to solve velocity, meanwhile the $\mathrm{dv} / \mathrm{dt}$ is to be done to solve the acceleration.

It shows the maximum force with different linkage length $\mathrm{L}=180 \mathrm{~mm}$. The periodic distribution of maximum three parameters is from $1 \mathrm{~s} \& 1 \mathrm{~s}$ to $0.85 \mathrm{~s}$, $0.75 \mathrm{~s} \& 0.67 \mathrm{~s}$ for speed with $300 \mathrm{r} / \mathrm{m}$ and $400 \mathrm{r} / \mathrm{m}$. The high efficiency is high one with long linkage length and high speed which causes high force and rapid work to apply to. Deep working with high force and deep movement is adopted big linkage length. It may be deduced from the formula which can incline the acceleration with long linkage so the force will be inclined correspondingly.

Figure $3(a, b)$ shows that movement of vehicle becomes sinusoidal wave when the time changes. Meanwhile the one does when the crank and linkage length changes. It will be sinusoidal from positive position to zero one then from zero to negative one finally becomes zero and positive one with a circle.when crank length is $100 \mathrm{~mm}$ and linkage length is $180 \mathrm{~mm}$ the highest movement is formed, then crank length is $85 \mathrm{~mm}$ and linkage length is $160 \mathrm{~mm}$ and the lowest movement is crank length is $70 \mathrm{~mm}$ and linkage one is $140 \mathrm{~mm}$. Here the role of crank length is a little and main is linkage length. Figure 3(c, d) shows the similar phenomenon with above Figure 3(a, b) mentioned. In total when speed is increased the movement will incline a little and the phase angle will decline.

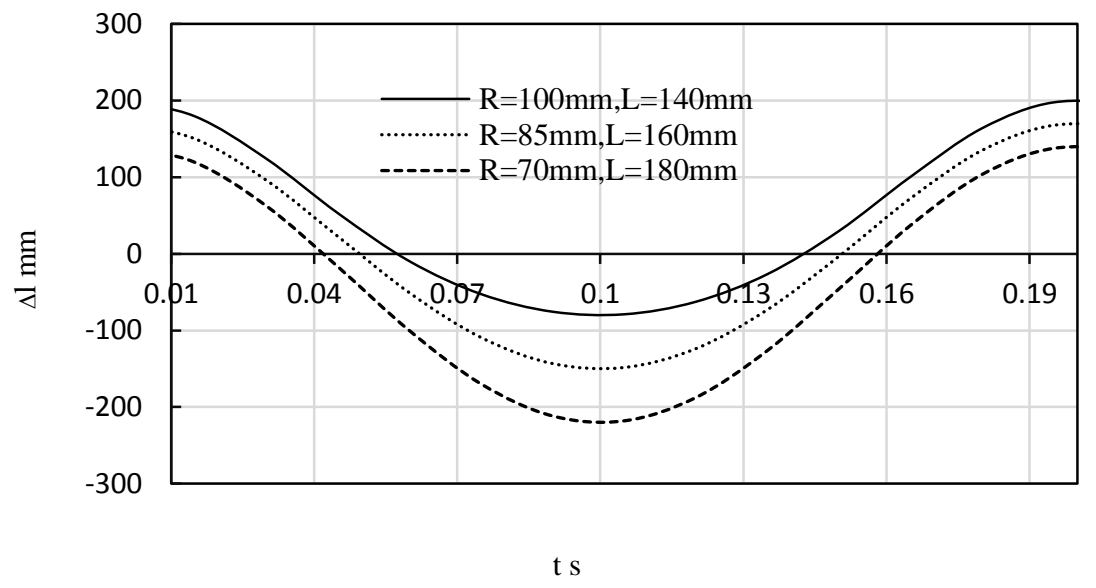

(a) $n=300 r / m$ 


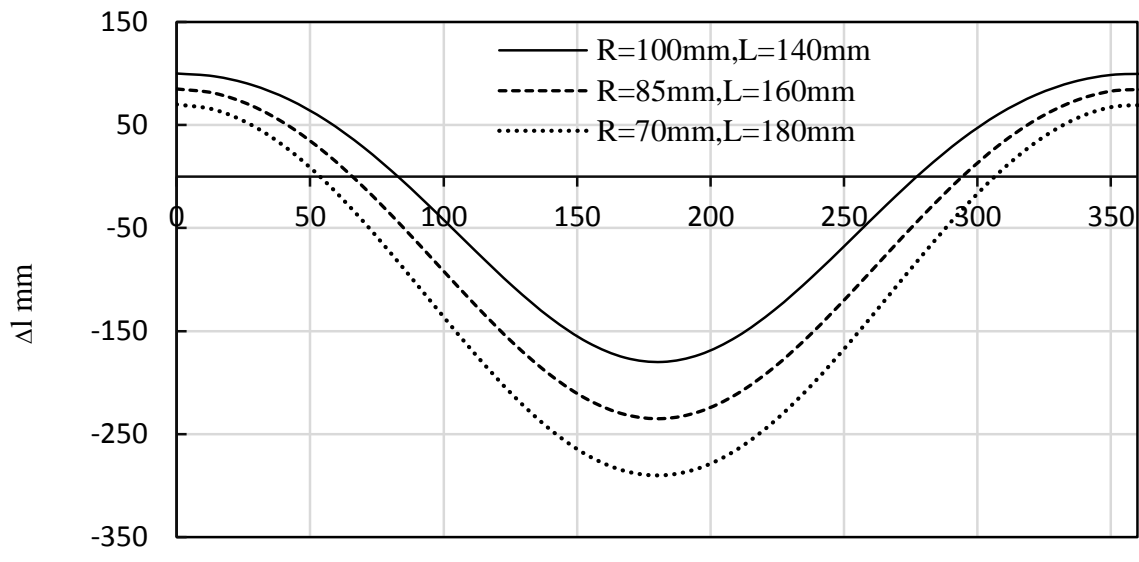

ts

(a) $n=300 \mathrm{r} / \mathrm{m}$

Fig-3: Relations of piston movement and time with the parameter $R$ \& $L$ under different speed

Figure 4(a,b) shows that with increasing crank length $\mathrm{R}$ from $70 \mathrm{~mm}$ to $85 \mathrm{~mm}$ the valley velocity becomes small. Meanwhile with increasing time it becomes sinusoidal wave, and with increasing linkage length it will incline from $5 \mathrm{~m} / \mathrm{s}$ to $-5 \mathrm{~m} / \mathrm{s}$ when the time is $0.04 \mathrm{~s}$. Figure $4(\mathrm{a}, \mathrm{b})$ shows that the velocity will be big with speed $400 \mathrm{r} / \mathrm{m}$. The similar status will be shown with Figure 4(a,b). The velocity becomes sinusoidal wave repeatedly when the time attains periodic second $0.2 \mathrm{~s}$ and it shows that velocity effect of linkage length turn is $180 \mathrm{~mm}>160 \mathrm{~mm}>140 \mathrm{~mm}$ with the increasing time in this study. In general the difference between them is about size with $1 \mathrm{~m} / \mathrm{s}$.

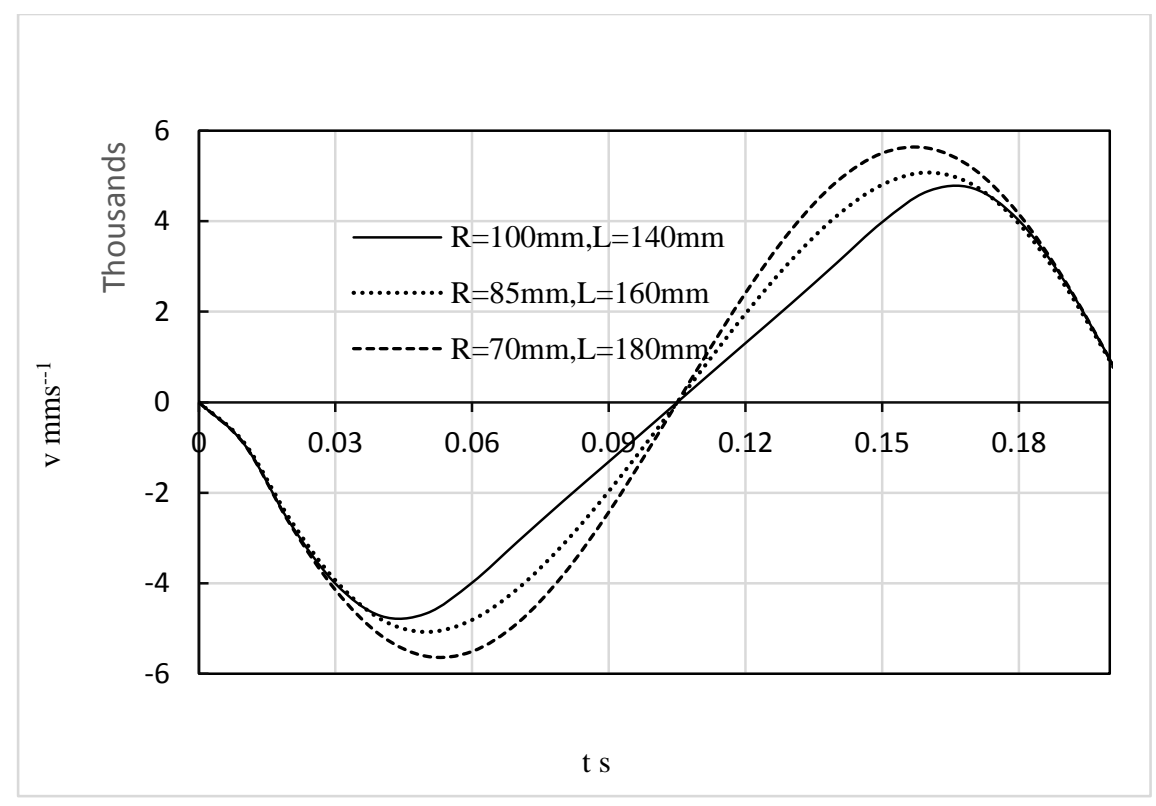

(a) $\mathrm{n}=300 \mathrm{r} / \mathrm{m}$ 


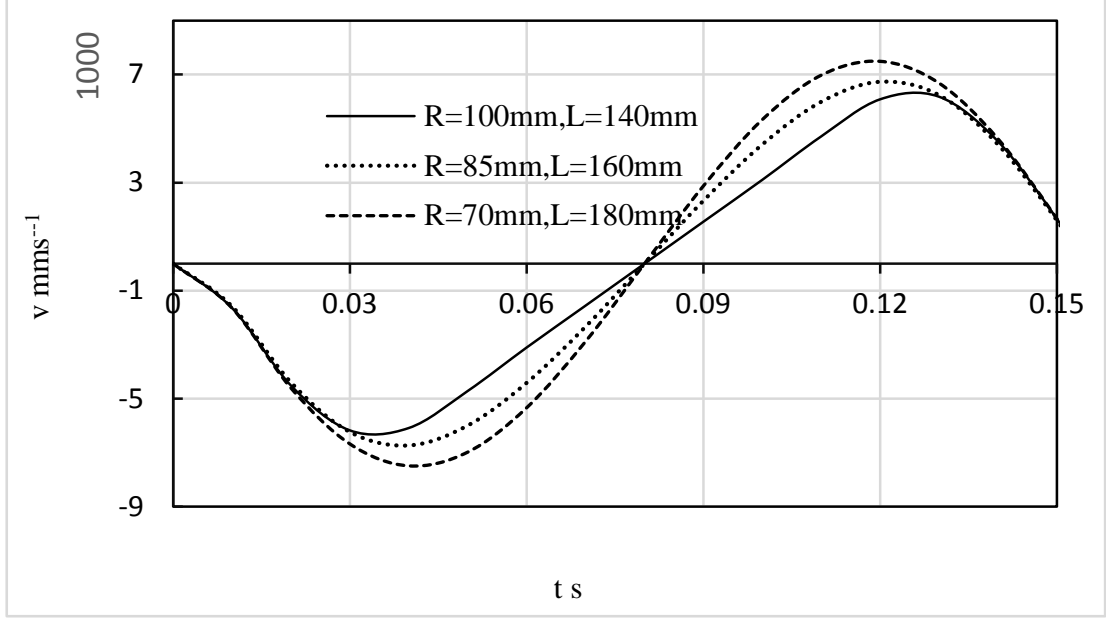

(b) $n=400 \mathrm{r} / \mathrm{m}$

Fig-4: Relations of acceleration and time with the parameter $R \& L$ under different speed

In Figure $4 \& 5$ shows the curve of velocity and acceleration of two parameters. The condition in this paper is $\mathrm{R}=70 \mathrm{~mm}, 85 \mathrm{~mm}$ and $100 \mathrm{~mm}$ and $\mathrm{L}=140 \mathrm{~mm}, 160 \mathrm{~mm}$ and $180 \mathrm{~mm}$. The similar status will be found too to compare with Figure-3. It is here not to be mentioned again. The mentioned point is with increasing from $n=300 \mathrm{r} / \mathrm{m}$ to $400 \mathrm{r} / \mathrm{m}$ the velocity will become big. That means that the high power will be formed here. The speed of $400 \mathrm{r} / \mathrm{m}$ is needed in heavy load such as the thick thickness steel strip and the deepest cavity in production manufacture. If the speed is big the velocity of vehicle becomes big as well. So increasing speed is to incline vehicle force from $300 \mathrm{r} / \mathrm{m}$ to $400 \mathrm{r} / \mathrm{m}$, it is one way to regulate. Another is that regulation of increasing linkage length to increase the force and velocity in a vehicle. Both of them are important to control the vehicle velocity and acceleration in designing a punch machine. The phase angle will be smaller at $400 \mathrm{r} / \mathrm{m}$ than the one at $300 \mathrm{r} / \mathrm{m}$ from $2 \mathrm{~s}$ to $0.15 \mathrm{~s}$ as shown in Figure 5(a,b).

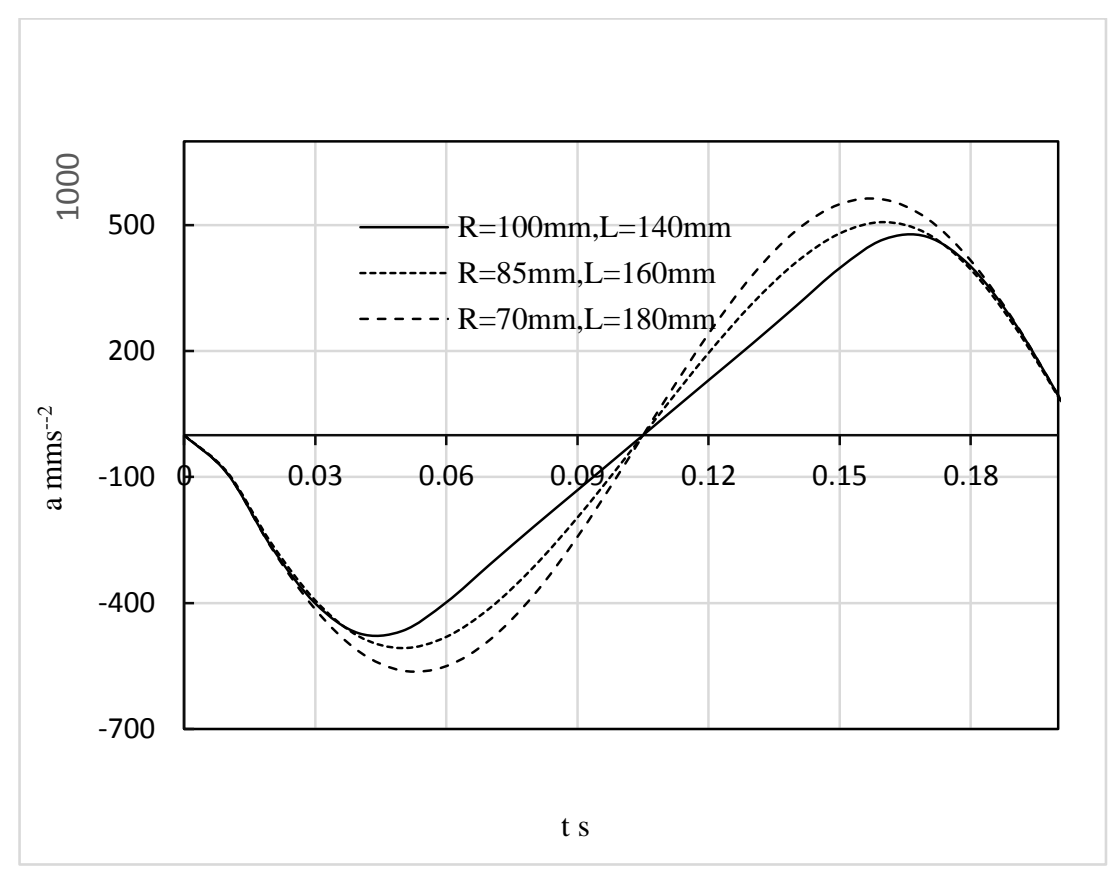

(a) $n=300 r / m$ 


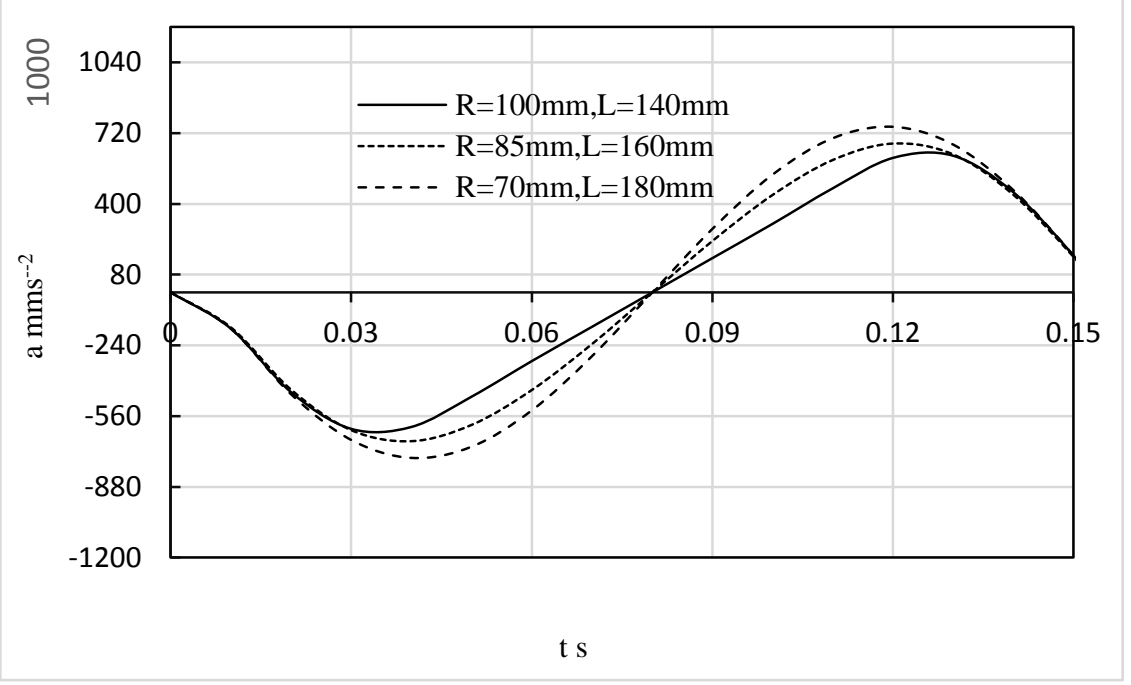

(b) $n=400 \mathrm{r} / \mathrm{m}$

Fig-5: Relations of speed and time with the parameter $R \& L$ under different speed

Figure 5(a c) shows that the acceleration forms sinusoidal when the time increases and then it forms sinusoidal wave under $n=300 \mathrm{r} / \mathrm{m}$ and $\mathrm{n}=400 \mathrm{r} / \mathrm{m}$. The summit was large when the time is 0.04 seconds, and then forms another summit with sinusoidal wave when the time is 0.12 seconds at $n=300 \mathrm{r} / \mathrm{m}$. Figure $5(\mathrm{~b})$ curves summit change to be larger at $n=400 \mathrm{r} / \mathrm{m}$ while the phase angle becomes small. It indicates that the acceleration summit increases with increasing speed, and repeats with speed. Figure 5(a,b) shows that the acceleration of the vehicle will incline within the first $0.04 \mathrm{~s}$ which is smaller than speed $\mathrm{n}=300 \mathrm{r} / \mathrm{m}$ when speed inclines to $400 \mathrm{r} / \mathrm{m}$. It explains the movement is zero with center line so the biggest stamping happens. However the opposition movement stamping forms second summit which is smaller than the first one. With increasing linkage length the acceleration will incline. In general the power will become strong when long linkage length is. In the place where it need small force the short linkage length is available for design. If the mass of first shaft is $2 \mathrm{Kg}$ the biggest force attains $160 \mathrm{Kg}$ at $19 \mathrm{Km} / \mathrm{h}$.

\section{CONCLUSIONS}

1. The movement of vehicle becomes sinusoidal wave when the time changes. With the increase of time the vehicle speed becomes sinusoidal repeatedly. When the crank length and linkage length is big the movement and velocity shows big one. So to incline the force it is chosen of big stroke length and high speed.
2. The similar status will happen in acceleration and the small acceleration summit forms then inclines at 0.04 seconds and $0.12 \mathrm{~s}$ subsequently in one cycle at $400 \mathrm{r} / \mathrm{m}$ which is smaller than the one at $300 \mathrm{r} / \mathrm{m}$. So as time goes up the acceleration goes up and it goes to maximum in one cycle. When the speed is big the acceleration inclines from $300 \mathrm{r} / \mathrm{m}$ to $400 \mathrm{r} / \mathrm{m}$.

\section{REFERENCES}

1. Wu, W. (2019). Kinematics analysis of crank linkage length mechanism of internal combustion engine for vehicle, Internal Combustion Engine and Accessories. 5:72

2. Run, X. (2020). Modeling of Economic Cost and Technological Control in Motor Housing Punch. Social Science learning Education Journal, $5(9): 315-324$

3. Run, X. (2020). The Simulation of Dynamics and Consumed Fuel on Rotary Inertia Vehicles, International Journal of Plant Engineering and Management, 25(2):1-12.

4. Shenghua, L., \& Longbao, Z. (2017). The Internal Combustion Engine to Learn, China Machine Press. 115-116

5. Run, X. U. (2019). The Cost Control of Motor Housing Process. International Journal, 24(3):187192.

6. Li, C., \& Lou, J. (2008). Dynamic analysis of crank railing mechanism of xingxing air compressor. Chinese Ship Research, 5(13), 98. 